\title{
Roscas as financial agreements to cope with self-control problems*
}

\author{
Stefan Ambec ${ }^{\dagger}$ and Nicolas Treich ${ }^{\ddagger}$
}

September 2005

\begin{abstract}
We consider a model in which people with limited self-control can sign binding financial agreements among themselves, thereby forming coalitions. We show that these financial agreements may help them to alleviate their self-control problems. We then demonstrate that there exists a stable structure of coalitions in which people form rotating savings and credit associations (roscas). We therefore provide a behavioral rationale for one of the most prevalent and puzzling financial institutions in developing countries. Finally, we derive and discuss some empirical predictions.
\end{abstract}

Key words: Rosca, Self-Control, Social Pressure, Stability, Contract, Credit. JEL classification: D14, G29, O17.

\footnotetext{
${ }^{*}$ We thank Jean-Luc Demonsant, Marcel Fafchamps, Alexander Koch, Shyama Ramani, two very helpful referees and a Co-Editor, as well as seminar participants at the University of Salerno, Laval University (Quebec), NEUDC 2002 (Williams College), DELTA (Paris), Oxford University, WZB conference on "Economics and Psychology" (Berlin), GATE (Lyon) for useful comments. This paper was initiated when the first author was TMR fellow at CSEF, University of Salerno, Italy. He acknowledges the European Commission under the RTN Program HPRN-CT-2000-00064 on "Understanding Financial Architecture" for its financial support and the University of Salerno for its hospitality. A previous version of this paper was entitled "Roscas as financial agreements to cope with social pressure."

${ }^{\dagger}$ Corresponding Author. Address: INRA-GAEL, University of Grenoble, BP 47, 38040 Grenoble Cedex 9, France, phone : 334768283 36, fax: 334768254 55, e-mail: ambec@grenoble.inra.fr.

${ }^{\ddagger}$ INRA-LERNA, University of Toulouse, France.
} 


\section{Introduction}

Rotating savings and credit associations (roscas) are one of the most prevalent forms of informal financial institution in developing countries. The basic principle of roscas is almost the same everywhere. A group of people gather for a series of meetings. At each meeting, everybody contributes to a common pot. The pot is given to only one member of the group. This member is then excluded from receiving the pot at future meetings, but still contributes towards it. This process is repeated until every member has received the pot. The rosca is then disbanded or begins another cycle. The pot may be allocated randomly (random roscas), or through a bidding process (bidding roscas). For random roscas, while the original allocation order is chosen randomly, the order of the winners may, or may not, be repeated throughout the cycles.

Roscas are very specific types of agreement. They stipulate a constant contribution to be paid at regular dates and with an equal lump-sum transfer to be received randomly in the future. Despite the high degree of specificity of these financial agreements, roscas exist on at least three continents (Africa, Asia, Latin America) and within very different communities (Bouman, 1977). They involve between $50 \%$ and $95 \%$ of the adult population in several African countries and mobilize about one-half of national savings in Cameroon (Bouman, 1995). The particular characteristics of roscas thus probably respond in some way to the needs of the population living in these countries.

The literature has mainly investigated two justifications for the existence of roscas. First, roscas may be viewed as a substitute to insurance, especially in developing countries where markets for insurance either do not exist or do not function well. Yet this interpretation applies only to bidding roscas (e.g. Calomiris and Rajaraman, 1998, Klonner, 2003), in which the allocation process responds to some individual specific shocks, and not to random roscas. Moreover, people who group together in a rosca generally belong to the same village and have similar occupations and income. For instance, Besley, Coate and Loury (1994) mention that the typical scenario is a group of individuals who work in the same office block or belong to the same community. This strong homogeneity within roscas is not really consistent with risk diversification purposes. 
Second, and more importantly, roscas may facilitate the purchase of durable goods. In their seminal contribution, Besley, Coate and Loury (1993) show that, on average, roscas allow individuals to buy the durable good sooner in their lifetime than by accumulating private savings. This interpretation applies for some random roscas. However, it does not apply for a common random roscas whereby, after one full cycle, the order of draws is repeated throughout subsequent cycles. Consequently, the member who receives the pot last could do as well by privately accumulating savings, while not suffering from the lack of flexibility in terms of the contribution schedule. This member is thus worse off. By backward induction, the rosca should break down. Furthermore, Gugerty (2000) found evidence against the durable good explanation from Western Kenya. She mentions that, in her survey, "over half of roscas participants use their rosca winning for more than one purpose, and one fifth use their winning for more than two purposes." Many rosca participants also indicate that they do not necessarily prefer to receive the pot sooner than later.

This paper examines a third justification based on a limited self-control hypothesis. It argues that the specific characteristics of roscas (constant and low contribution scheduled in advanced, high remuneration, inflexible and random ordering) help people to cope with their self-control problems. It relies on a simple model in which roscas emerge as an efficient financial agreement that people want to commit on.

The model works as follows. Individuals can purchase two types of good: standard goods (composite consumption) and a "superfluous" good. The superfluous good is subject to a self-control problem: its consumption yields a non-pecuniary lumpy benefit which has no anticipated value. It is modelled as time-inconsistent (or temporary) preferences. ${ }^{1}$ The other important aspect of this economy is that people are allowed to group together and to sign binding financial agreements among themselves. By signing a financial agreement, individuals form a coalition. We focus on stable coalition structures in the precise sense that no group of individuals has an incentive to deviate by signing another financial agreement. Our main result is that people in this economy are better-off by forming roscas than by designing any other kind of financial agreements.

\footnotetext{
${ }^{1}$ Temporary preference refers here to an extreme form of time-inconsistency: the consumption of the superfluous good induces some strictly positive value only during the consumption period.
} 
This paper is not the first to introduce the idea of limited self-control as a potential rationale to explain roscas. Recently, the economic literature has complemented the durable good motive for forming roscas by suggesting that roscas may also serve as a commitment device to save (Gugerty, 2000, Aliber, 2001, Anderson and Baland, 2002). This development has been inspired by at least two factors.

First, an abundant literature in psychology and economics suggests that many individuals suffer from self-control and time-inconsistency problems (Akerlof, 1991, Ainslie, 1992, Thaler, 1992, O'Donoghue and Rabin, 1999). Commitment techniques that restrict individuals' choice in the future can help to overcome these inconsistencies. It has been observed that many commitment savings products exist in developing countries (Ashraf et al., 2003). It is natural to see roscas as a commitment function as well.

Second, some survey studies indicate that rosca members often report self-control problems as their main reason for joining roscas. For instance, people report that "You can't save aloneit is easy to misuse money", "Sitting with other members helps you to save", "It is difficult to keep money at home as demands are high" in Gugerty (2000). In Henry and al. (1990), a rosca member says that "When one wants to save money, joining a rosca forces one to save a little" (our translation). In Kuper and Kaplan (1944) (quoted in Aliber, 2001), people comment that "The contribution is not much, and I would spend it in any case on nothing" ; "Because I could not save when I was alone the [rosca] helps me to save". In Aliber (2001), a member confesses that he 'feel[s] obliged to pay and therefore benefit in that it is a saving scheme of some sort". People seem to have some difficulties in sticking to a consumption plan. They have a tendency to spend money for purposes other than the ones originally planned.

Self-control problems may be approached at the household level as well. This idea is formalized in Anderson and Baland (2002). They consider an intra-household bargaining model. In this model, at a point in time the wife loses the full control of the household's expenditures. But she wants to keep some money out of her husband's control in order to buy a durable good. Ex ante, she thus may find it useful to belong to a rosca. Even if our model differs from Anderson and Baland's, both models argue that a temporal disagreement (among different "selves" or within a household) explains rosca participation.

In the same vein, self-control problems might be caused by social pressure from relatives 
or community members. People in developing countries are involved in networks of relations with strong norms and obligations enforced by social pressure. Although we model limited self-control as a pure individual problem, we contend that social relations and peer-pressure may be at the origin of self-control problems or exacerbate them. For instance, the desire to purchase superfluous goods may be triggered by a specific social or economic context. It is well-known that people tend to purchase some specific goods during social events, e.g., gifts, alcohol, food. They might enjoy the instantaneous social gratification from doing so, or else feel guilty if they do not. Typically, in developing countries people are pressed to distribute a part of their income, to assist their relatives, as an informal taxation system. Anthropological studies emphasize the importance of such a social norm in traditional societies (see Parkin, 1972, Scott, 1976, James 1979, Platteau, 1996, among others). As argued in Fafchamps (1995), people suffer from internalized moral sanction when they deviate from this social code and/or enjoy some rewards when they comply with it. Sanctions and gratifications are thus created through social pressure within the community. For instance, people may publicly disapprove of those who accumulate wealth without sharing it within the community (James 1979, Platteau 1996). On the other hand, the community may reward generous donors during social events in the form of social prestige for instance (see Parkin, 1972, regarding the rules of ceremonies in which donors are thanked). The act of giving to the community may therefore be a sort of emotional response to this social pressure, ${ }^{2}$ and can arguably be viewed as a purchase of a superfluous good from an ex ante point of view. The main result of the paper could then be reformulated. A rosca may be useful for people pressed by their relatives to share their income. The basic idea is that individuals belonging to a rosca commit to contribute a fixed amount in the future. As a result, participating in a rosca reduces their future available income, and thus reduces their future vulnerability to social pressure. As Platteau (2000, page 231) put it: "[Roscas] provide a socially accepted alibi to protect people's saving against all sorts of social

\footnotetext{
${ }^{2}$ Elster (1998, page 70) writes: "The person who sees a beggar in the street and feels an urge to give him money, or the person who is in the grip of shame and feels an urge to kill himself, may be viewed as undergoing a short-term change of preferences. It is in fact an important feature of many occurrent emotions that they have relatively short duration". If we follow Elster, we should think of these emotions as a form of temporary preference.
} 
pressure". ${ }^{3}$

Our model yields theoretical predictions that are fairly consistent with several empirical case studies. First, roscas mostly attract average-income individuals, as apposed to very poor or very rich. Second, members are homogeneous within roscas. Third, across roscas the contribution increases with the revenue of members. Fourth, the amount contributed is inversely related with the size of the rosca.

Our paper is not the first to model the formation of stable informal agreements in developing countries. Genicot and Ray (2003) examine self-enforcing informal risk-sharing agreements within that are robust to the deviation of a subgroup of individuals. However, their analysis of stability is different. Genicot and Ray (2003) examine deviation by subgroups anytime in a repeated relationship. Here, the financial agreements are binding. We impose stability only at the initial contracting stage.

The rest of the paper proceeds as follows. Section 2 introduces the model. Sections 3 and 4 characterize the stable financial agreement in a static framework. Section 5 extends the analysis to a dynamic framework and shows that roscas are stable financial agreements. Section 6 relates some implications of our theoretical analysis with empirical evidence from several case studies. Finally, Section 7 concludes the paper. All proofs are presented in the Appendix.

\section{The Model of Limited Self-Control}

Consider an economy with an infinity of individuals $i \in \mathbb{N}$ living for several periods. In each period, individual $i$ has income $y_{i}$. He may consume his entire income and the utility of pure consumption is denoted $u_{i}\left(y_{i}\right)$. Every individual $i$ has also the option of buying one superfluous good per period at a cost $m_{i}$. This good yields a non-pecuniary lumpy benefit (or utility) of $S_{i}>0$.

\footnotetext{
${ }^{3}$ Similarly, Belsey (1995, page 117) highlights that the "anthropological literature makes clear the importance of social constraints that can make saving unattractive. Certain familial obligations can be difficult to resist, so that part of any stock of savings may be paid as a transfer." Also Ashraf et al. (2003) state that "If less cash is in hand, or savings are not easily accessed, then an individual is more empowered to turn dow requests for withdrawals or loans from family or peers."
} 
We now introduce the self-control problem. We consider a variant version of the "betadelta" model leading to the classical time-inconsistency problem. This model was introduced by Phelps and Pollack (1968) for intergenerational discounting and used by Laibson (1997) for intra-personal discounting. In period 1 , the utility function of individual $i$ writes as follows

$$
u_{i}\left(y_{i}-I_{1} m_{i}\right)+I_{1} S_{i}+\beta^{u} \sum_{t=2} \delta^{t-1} u_{i}\left(y_{i}-I_{2} m_{i}\right)+\beta^{S} \sum_{t=2} \delta^{t-1} I_{t} S_{i}
$$

where $I_{t}$ are the discrete choice variables in the model, each of which can assume a value of either zero or one in each period. Parameter $\delta$ is the per period discount factor. Parameters $\beta^{u}$ and $\beta^{S}$ allow for the possibility of non-exponential discounting derived respectively from the stream of utility and from the stream of consumption of the superfluous good. To simplify, we assume $\beta^{u}=1$ and $\beta^{S}=0$ : we have thus the standard exponential discounting for the former and an extreme form of hyperbolic discounting for the latter.

Before we proceed further with the model a comment is in order. Notice that, besides this extreme form of hyperbolic discounting for the superfluous good, we have assumed that the superfluous good is of fixed size and indivisible, and that at most one unit can be purchased. Hence the modelling of the superfluous good is quite specific. However, this shall not obscure the main point that roscas can mitigate self-control problems in general. As we will see, this form of hyperbolic discounting towards the superfluous good yields a non-concavity the utility function, which will be instrumental for explaining the willingness to participate in roscas. Yet, the standard "beta-delta" model may also yield local non-concavities for some utility functions (e.g., Luttmer and Mariotti, 2004). As a result, roscas can also be shown to be valuable in the more standard "beta-delta" model (an example is given in Gugerty, 2000).

In such a model, in each period $t$, it is optimal for any individual $i$ to buy the superfluous good if and only if

$$
u_{i}\left(y_{i}-m_{i}\right)+S_{i}>u_{i}\left(y_{i}\right) .
$$

We assume that $u_{i}($.$) is defined and differentiable on \mathbb{R}_{+}$. It is also increasing and concave. In words, poor people attach relatively less value to the superfluous good compared to current consumption than do richer people.

With our extreme form of hyperbolic discounting, $S_{i}$ has no value from an ex ante point of view. Viewed from period $t-1$ and before, it will never be optimal for $i$ to buy the superfluous 
good in period $t$ since:

$$
u_{i}\left(y_{i}-m_{i}\right)<u_{i}\left(y_{i}\right)
$$

However individual $i$ anticipates that, at time $t$, it will be optimal for him to buy the superfluous good. In other words, we consider time-inconsistent sophisticated individuals. At every period, the individual cannot resist to buy the good since (1) holds. Yet, he knows this in advance and wants to be able to resist to it because spending $m_{i}$ is a pure loss from an ex ante viewpoint.

Note that, under concavity, there exists a unique revenue $\underline{y}_{i}$ that makes an agent indifferent between spending $m_{i}$ or not:

$$
u_{i}\left(\underline{y}_{i}-m_{i}\right)+S_{i}=u_{i}\left(\underline{y}_{i}\right)
$$

Clearly, $\underline{y}_{i}$ exists and is unique because the marginal gain of renouncing to $S_{i}, u_{i}(y)-u_{i}\left(y-m_{i}\right)$, is decreasing with $y$. To summarize, for any $y \in \mathbb{R}^{+}$, one can define an agent ex ante utility in each period by:

$$
v_{i}(y)=\left\{\begin{array}{lll}
u_{i}\left(y-m_{i}\right) & \text { if } & y>\underline{y}_{i} \\
u_{i}(y) & \text { if } & y \leq \underline{y}_{i}
\end{array} .\right.
$$

This function is given by the thick line in Figure 1 shown below.

\section{[INSERT FIGURE 1 HERE]}

The downward jump in the ex ante utility function generates a non-concavity. This implies that people could be better off by randomizing their revenue by playing lotteries. In the next section, we investigate what kind of lotteries they would like to play.

\section{Efficient Lotteries}

In this section, we examine the lottery that an individual $i$ would like to play. Let us first define a lottery.

Definition 1 A lottery $\mathcal{L}_{j}=\left(K, p, T_{j}\right)$ is defined by: ${ }^{4}$

\footnotetext{
${ }^{4}$ Notice that, in this definition, we choose to map the probability measure $p$ on the set of states of nature rather than directly on the set of transfers.
} 
- A set of states of nature $K=\{1, \ldots, k\}$.

- A probability measure $p$ on $K$ where $p(l)$ denotes the probability of state $l$ for any $l \in K$.

- A set of transfers $T_{j}=\left\{t_{j}^{l}\right\}_{l \in K}$ where $t_{j}^{l}$ denotes the transfer assigned in state $l$.

If individual $i$ accepts lottery $\mathcal{L}_{j}$, he faces an ex ante utility:

$$
U_{i}\left(\mathcal{L}_{j}\right)=\sum_{l \in K} p(l) v_{i}\left(y_{i}+t_{j}^{l}\right)
$$

The expected payoff of a lottery is defined by:

$$
x_{j} \equiv \sum_{l \in K} p(l) t_{j}^{l} .
$$

A lottery with zero expected payoff, i.e. $x_{j}=0$, will be referred as "fair".

An efficient lottery $\mathcal{L}_{i}^{*}$ maximizes $i$ 's expected utility (as defined in 5 ) for a given expected payoff $x_{i}$. In Lemma 1, we characterize the transfers of such an efficient lottery.

Lemma 1 Any efficient lottery assigned to an individual $i$ randomizes between two transfers $t_{i}^{1}=\underline{y}_{i}-y_{i}$ and $t_{i}^{2}$ such that

$$
\frac{u_{i}\left(y_{i}-m_{i}+t_{i}^{2}\right)-u_{i}\left(y_{i}+t_{i}^{1}\right)}{t_{i}^{2}-t_{i}^{1}}=u_{i}^{\prime}\left(y_{i}-m_{i}+t_{i}^{2}\right) .
$$

A graphical analysis can be useful to understand the intuition leading to Lemma 1. The expected payoff of an efficient lottery can easily be represented. The outcome of any draw is an ex post revenue $y_{i}+t_{i}^{l}$ which translates into ex ante utility $v_{i}\left(y_{i}+t_{i}^{l}\right)$. Graphically, it is a point on $v_{i}$. A lottery which randomizes between only two states and the associated transfers $t_{i}^{1}$ and $t_{i}^{2}$ defines two points $\left(y_{i}+t_{i}^{1}, v_{i}\left(y_{i}+t_{i}^{1}\right)\right)$ and $\left(y_{i}+t_{i}^{2}, v_{i}\left(y_{i}+t_{i}^{2}\right)\right)$. The expected utility of such a lottery is located on the straight line that links those two points, e.g. line $g$ in Figure 2 below.

\section{[INSERT FIGURE 2 HERE]}

The exact location on this line depends of the expected payoff on the lottery. For instance, with a fair lottery, the expected utility is located at the intersection of $g$ and a vertical axis starting from $y_{i}$, labelled $h$. Finding an efficient fair lottery amounts to finding a straight line that maximizes the ordinate of the intersection of $g$ and $h$. This line, denoted $g^{*}$, is the set of 
efficient lotteries. It must be the upper straight line that links two points, one in the portion $u_{i}(y)$ and the other on the portion $u_{i}\left(y-m_{i}\right)$ of $v_{i}$. It therefore goes from $\left(\underline{y}_{i}, u_{i}\left(\underline{y}_{i}\right)\right)$ and is tangent to the curve $u_{i}\left(y-m_{i}\right)$. The tangency condition of $g^{*}$ to $u_{i}\left(y-m_{i}\right)$, formally $(7)$, defines $t_{i}^{2}$ or, equivalently $\bar{y}_{i} \equiv y_{i}+t_{i}^{2}$.

Denoting $\mu$ (resp. $1-\mu$ ) the probability to pay $-t_{i}^{1}$ (resp. to receive $t_{i}^{2}$ ), an efficient lottery for individual $i, \mathcal{L}_{i}^{*}$, yields to individual $i$ an expected payoff

$$
U_{i}\left(\mathcal{L}_{i}^{*}\right)=\mu u_{i}\left(\underline{y}_{i}\right)+(1-\mu) u_{i}\left(\bar{y}_{i}-m_{i}\right),
$$

located along the line $g^{*}$. In the next section, we show that the stability condition imposes restrictions on the expected payoffs of lotteries which picks up a single lottery among the set of efficient lotteries, i.e. the fair one.

\section{Stable Financial Agreements}

We now turn to the design of financial agreements. As a first step, we restrict our attention to a static framework. At the beginning of the period, at date 0 say, people may sign financial agreements. After this contracting stage, an equilibrium structure of financial agreement emerges in the economy. Then agreements are carried out. Each agent performs transfers as specified in the contract and then either buys the superfluous good or not, depending on his remaining wealth.

We need to introduce more definitions. First, let us first formally define what we call a "financial agreement" (FA). In short, a FA is a contract among a group of agents assigning payments among them (including random payments). It is assumed binding: people cannot default (or at infinite cost). The random procedure (if any) and payment structure are freely chosen by agents so that no restrictions are imposed on the space of contracts. Formally, a FA is defined as follows.

Definition 2 A financial agreement $\mathcal{C}_{j}=\left(N_{j},\left\{\mathcal{L}_{i}\right\}_{i \in N_{j}}\right)$ is defined by:

- A set of agents $N_{j} \subset \mathbb{N}$

- A set of lotteries $\left\{\mathcal{L}_{i}\right\}_{i \in N_{j}}=\left\{\left(K_{j}, p_{j}, T_{i}\right)\right\}_{i \in N_{j}}$ with common set of states of nature $K_{j}=\left\{1, \ldots, k_{j}\right\}$ and probability measure $p_{j}$ on $K_{j}$. 
- Lotteries are budget-balanced state-by-state: $\sum_{i \in N_{j}} t_{i}^{l}=0$ in each state of nature $l \in K_{j}$.

In words, a financial agreement defines a group of members $N_{j}$ who perform random transfers or lotteries $\left\{\mathcal{L}_{i}\right\}_{i \in N_{j}}=\left(K_{j}, p_{j}, T_{i}\right)$ among themselves, which are budget balanced in each draw.

Because transfers are budget balanced state-by-state, the expected payoff of lotteries sumup to zero within any FA:

$$
\sum_{i \in N_{j}} x_{i}=\sum_{l \in K_{j}} p_{j}(l) \sum_{i \in N_{j}} t_{i}^{l}=0
$$

We now turn to our definition of stability. Denote $\mathbf{C}=\left\{\mathcal{C}_{j}\right\}_{j \in \mathbb{N}}$ a structure of financial agreements (SFA). It has to be stable in the sense defined below.

Definition 3 A structure of financial agreements $\mathbf{C}^{*}=\left\{\mathcal{C}_{j}^{*}\right\}_{j \in \mathbb{N}}=\left\{\left(N_{j}^{*},\left\{\mathcal{L}_{i}^{*}\right\}_{i \in N_{j}^{*}}\right)\right\}_{j \in \mathbb{N}}$ is stable if, no other $F A \mathcal{C}_{j}^{\prime}=\left(T,\left\{\mathcal{L}_{i}^{\prime}\right\}_{i \in T}\right)$ is such that

- $U_{i}\left(\mathcal{L}_{i}^{\prime}\right) \geq U_{i}\left(\mathcal{L}_{i}^{*}\right)$ for every $i \in T$.

- $U_{h}\left(\mathcal{L}_{h}^{\prime}\right)>U_{h}\left(\mathcal{L}_{h}^{*}\right)$ for at least one $h \in T$.

A SFA is stable if no group of agent can be better-off by designing another FA. When it is not the case, this group would deviate and agree on its own FA. Stability is defined in the sense of the core. A group of agents would "block" a structure of financial agreements if this group can improve the payoff of its members by deviating and forming its own financial agreement. To be stable, a structure of financial agreement must not be blocked by any group of individuals. Notice that stability implies Pareto efficiency but the reverse is not true. ${ }^{5}$ As a consequence a stable SFA contains only efficient lotteries. Thus, Lemma 1 which characterizes efficient lotteries applies. We now examine the implications of stability for these efficient lotteries.

Lemma 2 A stable SFA includes only efficient and fair lotteries.

\footnotetext{
${ }^{5}$ For instance a SFA which includes FAs that yield different expected payoffs to identical agents might be efficient (according to the Pareto criterium) but not stable: Those whose expected payoffs are the lowest could be better-off by forming their own FA at the expense of the others.
} 
Lemma 2 states that no individual subsidizes other people by playing negative-expectedpayoff lotteries. If it was the case, such an individual would be better-off by forming another FA in which he would play a zero-expected-payoff (i.e. fair) and efficient lottery. Formally, Lemma 2 imposes the following restriction on the probability distribution $\mu_{i}$ :

$$
\mu_{i} t_{i}^{1}+\left(1-\mu_{i}\right) t_{i}^{2}=0
$$

We have established that the highest payoff that any arbitrary agent can achieve in a stable structure of FAs is:

$$
U_{i}\left(\mathcal{L}_{i}^{*}\right)=\mu_{i} u_{i}\left(y_{i}+t_{i}^{1}\right)+\left(1-\mu_{i}\right) u_{i}\left(y_{i}-m_{i}+t_{i}^{2}\right)
$$

where $t_{i}^{1}, t_{i}^{2}$ and $\mu_{i}$ are, respectively, defined by Lemma 1 and by (10). This payoff can be

achieved if $i$ forms a group of size $n_{i}=\frac{1}{1-\mu_{i}}$ with other people with identical needs for $t_{i}^{1}$ and $t_{i}^{2}$ and if, in this group, the members contribute $-t_{i}^{1}$ to a pot assigned randomly to one single person. The size of the pot is then $t_{i}^{2}=\frac{\mu_{i}}{1-\mu_{i}}\left(-t_{i}^{1}\right)$. This FA yields to $i$ an expected utility level of

$$
U_{i}\left(\mathcal{L}_{i}^{*}\right)=\frac{n_{i}-1}{n_{i}} u_{i}\left(y_{i}+t_{i}^{1}\right)+\frac{1}{n_{i}} u_{i}\left(y_{i}-m_{i}+\left(n_{i}-1\right)\left(-t_{i}^{1}\right)\right),
$$

located where $g^{*}$ crosses $h$ in Figure 2. We now turn to the multi-period problem.

\section{Multi-Period Model}

This section extends previous results to the multi-periodic framework we first introduced in Section 2. Before any transfer, the preferences of individual $i$ at date 0 are thus simply

$$
\sum_{t=1}^{\infty} \delta^{t} v_{i}\left(y_{i}\right) .
$$

As before, any individual can design and sign binding financial agreements with the other individuals. Negotiations take place only at date 0. Saving is not allowed.

Let us now compute the intertemporal utility of an individual $i$ who belongs to a $n_{i}$ persons rosca. First, when he joins the rosca, he does not know in which period he will have the pot. Moreover, this individual knows that if he wins the pot in some period then he will be excluded from the draw in the subsequent periods during a cycle. So, each cycle, he is sure to get the pot 
exactly once. There is thus a probability $\frac{1}{n_{i}}$ that he will have the pot at date $h$ for each date of the cycle. In this case, his payoff will be $v_{i}\left(y_{i}+\left(n_{i}-1\right)\left(-t_{i}^{1}\right)\right)=u_{i}\left(y_{i}-m_{i}+\left(n_{i}-1\right)\left(-t_{i}^{1}\right)\right)$ in period $h$ and $u_{i}\left(y_{i}+t_{i}^{1}\right)$ in the other periods $t=1, \ldots, n_{i}, t \neq h$. Hence, the intertemporal utility at date 0 for the first cycle of any member $i$ of the rosca is simply,

$$
\sum_{h=1}^{n_{i}} \frac{1}{n_{i}}\left[\sum_{t=1, t \neq h}^{n_{i}} \delta^{t} u_{i}\left(y_{i}+t_{i}^{1}\right)+\delta^{h} u_{i}\left(y_{i}-m_{i}+\left(n_{i}-1\right)\left(-t_{i}^{1}\right)\right)\right] .
$$

This simplifies to

$$
\sum_{t=1}^{n_{i}} \delta^{t}\left[\frac{n_{i}-1}{n_{i}} u_{i}\left(y_{i}+t_{i}^{1}\right)+\frac{1}{n_{i}} u_{i}\left(y_{i}-m_{i}+\left(n_{i}-1\right)\left(-t_{i}^{1}\right)\right)\right] .
$$

Since, viewed from date 0 , the expected outcome of all cycles are identical, the extension to an infinity of periods is straightforward. The payoff at date 0 of any member of the rosca of an infinity of periods is thus equal to

$$
\sum_{t=1}^{\infty} \delta^{t}\left\{\frac{n_{i}-1}{n_{i}} u\left(y_{i}+t_{i}^{1}\right)+\frac{1}{n_{i}} u\left(y_{i}-m_{i}+\left(n_{i}-1\right)\left(-t_{i}^{1}\right)\right)\right\} .
$$

Observe now that this last expression is the exact multi-periodic extension of the static expression (12) obtained in the previous section. Hence, any individual may get the same expected utility by forming a rosca as by playing efficient lotteries in each period. Nevertheless, this does not mean that a rosca is an efficient lottery over the space of all possible lotteries. Indeed, one needs to consider the space of all "dynamic lotteries", not only the space of static ones. Typically, a rosca is not a static lottery since the probability that an individual gets the pot depends on previous draws. The next theorem, formally proved in Appendix C, extends previous results for such dynamic lotteries.

Theorem A structure of financial agreement composed by random roscas is stable.

The above theorem establishes that roscas are stable financial contracts. The proof is similar to that derived in the static framework. First, we show that Lemma 1 applies so that individual $i$ 's efficient lottery randomizes between only two transfers, $t_{i}^{1}$ and $t_{i}^{2}$, at any date $t$. Second, we show that any group of agent cannot improve their gain by deviating from a SFA composed of roscas. 
So, why is a rosca efficient in our model? Intuitively, our explanation relies on the existence of the self-control problem. We have represented an economy where an individual will be tempted to purchase the superfluous good if he is rich enough. However, today he derives no utility from this future purchase. Hence, a helpful financial agreement reduces this individual's future available income so that he will no longer be inclined to spend $m_{i}$ to purchase the good. This may be done by paying a fixed contribution $t$ committed in advance at regular dates. However, this contribution $t$ should not be a pure loss. As there are an infinite number of contributors in the economy, people with the same contributions $t$ pool together in a group. ${ }^{6}$ The sum of the contributions of the group is then collected and redistributed to only one member. Thus, only this latter individual spends $m_{i}$ in order to purchase the superfluous good. This explains why roscas are stable efficient agreements. A rosca minimizes the purchase of superfluous goods in every period since they are bought by only one member during the period he or she receives back the total of his own contributions.

\section{Empirical Predictions}

This theoretical result raises the question of whether there is some empirical support for our model. Key parameters such as the non-pecuniary benefit $S_{i}$ are unobservable. Besides, our main point was that people would want to find an ex ante device to escape future over-spending in superfluous goods. It is difficult to have empirical support for this point since it requires evidence of time-inconsistent preferences. A weak form of evidence relies on people's declarations in surveys (see the Introduction). Another form is related to the observed demands for commitment techniques. ${ }^{7}$ But it is probably difficult to obtain strong direct empirical support for our behavioral model. An indirect way is to derive and discuss theoretical implications. This is the objective of this section.

To simplify, revert to Figure 2. Observe that any individual $i$ with an income below $\underline{y}_{i}$ or

\footnotetext{
${ }^{6}$ The assumption that there is an infinite number of people in the economy is thus not innocuous. If that were not the case, the financial agreement would introduce a compromise to account for member's heterogeneous contributions. This may explain for instance the existence of roscas with variable contributions documented by Henry et al. (1990) in Cameroon.

${ }^{7} \mathrm{~A}$ recent natural experiment (Ashraf et al., 2004) developed in the Philippines relates demands for commitment savings products to hyperbolic discounting.
} 
above $\bar{y}_{i}$ will not participate in a rosca. The idea is that poor individuals are not tempted by superfluous goods and therefore have no interest in participating in a rosca. Conversely, very rich individuals would have to pay a very high contribution in order to be poor enough to be able to resist purchasing the superfluous good. As a result, it is too costly for them to participate in a rosca.

Moreover, note that any individual $i$ with initial income $y_{i} \in\left[\underline{y}_{i}, \bar{y}_{i}\right]$ increases his expected utility if he participates in a rosca. To do so, he must form a rosca with people who have the same needs for transfers, i.e., a rosca where the contribution is $-t_{i}^{1}=y_{i}-\underline{y}_{i}$ and where the received transfer is $t_{i}^{2}=\bar{y}_{i}-y_{i}$. The budget constraint implies that he will form a rosca with $n_{i}$ persons where

$$
n_{i}=\frac{t_{i}^{2}-t_{i}^{1}}{-t_{i}^{1}}
$$

From these observations, we can easily derive three clear-cut predictions:

- \#1 Average-income individuals are more likely to belong to a rosca compared to very poor or very rich people;

- \#2 Within roscas, members are homogeneous and, across roscas, the contribution increases with the members' income;

- \#3 When the contribution is relatively larger, the size of the group is relatively lower.

Some empirical findings are fairly consistent with these predictions. First, Anderson et al. (2002) interviewed people living in a poor slum in Kenya. They showed that roscas' participants are more likely to have a higher income. Since this study concerned a very poor population, it somehow gives support to prediction \#1. Along the same line, Levenson and Besley (1996) provide evidence that participation is higher among high-income households in Taiwan.

Several studies seem to be fairly consistent with the first part of prediction \#2 (i.e., homogeneity within roscas). In Uganda, rosca members reported that homogeneity in terms of income level and gender is important for the success of a rosca (Wright and Mutesasira, 2001). In Gambia, Nagarajan, Meyer and Graham (1999) who study a rosca called "osusu" indicate that: "While three-fourths of the sampled osusus were composed of occupationally homogenous 
members, about two-thirds were composed of members homogenous in age or gender. About half of the sampled osusus were simultaneously homogenous in gender, age and employment type." In Jamaica, Handa and Kirton (1999) found that there is high homogeneity among roscas' members.

Also Handa and Kirton indicate that there are two main broad categories of rosca in their Jamaican panel. The first and most common type is a rosca with many members and with a small contribution. The second and less frequent type of rosca has fewer and richer members, meets at longer intervals and has a larger size of contribution. The latter findings are thus consistent with our prediction \#3, along with the second part of \#2. The underlying economic idea is that, all things being equal, individuals with low (large) incomes will need a low (large) contribution to reduce their available income appropriately. They moreover need more (fewer) contributing members in order to get the desired pot.

The above predictions are generally not unique to our behavioral model. For example, prediction \#1 could be generated in a durable good model à la Besley, Coate and Loury (1993). Wealthier people would have enough money to buy the durable good, and poorer people would simply have no excess income to contribute to the rosca. Nevertheless, further evidence supports the self-control hypothesis.

First, Aliber (2001) observes that types of occupation explain most of the differences in the frequency of rosca meetings in his South African sample. He distinguishes between daily, weekly and monthly roscas. Strikingly, all people working in the formal sector prefer a monthly basis for meetings. He observes that monthly contributions also tend to coincide with the end-of-the-month pay schedule. This can easily be explained in terms of a limited self-control hypothesis. People who are paid on a monthly basis do not need to meet every day or every week. In order to reduce their available monthly income, it is sufficient for them to pay a contribution once a month to the other rosca members. Moreover, Aliber (2001) observes that most rosca members $(42 \%)$ prefer to be the last one to receive the pot rather than the first (14\%). Again, this last observation is not really consistent with the durable good explanation.

Roscas seem to be very popular among bank employees. For instance, Bouman (1995) reports that $75 \%$ of the Agricultural Bank staff in Egypt were members of a rosca. Similarly, 
Adams and Canavesi de Sahonero (1978) find surprising that in Bolivia roscas "were common among employees of most formal financial intermediaries: Commercial banks, development banks, the Central Banks, and the apex organization of the credit unions". They conclude that "this raises interesting questions about the benefits employees realize from participating in pasanakus [i.e. the local rosca] that they cannot realize from the financial institution in which they work." It is not easy to relate these observations to the durable good hypothesis. Bank employees have a better access to credit than most people living in developing countries. They should therefore be less likely to rely on roscas to finance a durable good. However, there are some reasons why bank employees may want to make their savings less easily accessible in the future. First, they may also be tempted by superfluous goods. A rosca is then an efficient way to sometime alleviate this temptation if they are wealthy enough (but not too wealthy). Second, due to their occupation, bank employees may face substantial social pressure to share their income. Hence belonging to a rosca may help them to turn down requests from peers or relatives more easily. This explanation thus relies on our hypothesis that some self-control problems may be linked to a phenomenon of social pressure.

Similarly, Anderson et al. (2002) note that people who have permanent positions and who have lived longer in the slum under study are more likely to participate in roscas. Again, people who have a relatively more stable occupation and a more stable place to live are more likely to be pressed to share their income. They may therefore want to find a device enabling them to resist to this social pressure. As a result, they may be more likely to participate in roscas.

We conclude this section on empirical predictions with two brief remarks about our model. First, in usual roscas, winners are excluded from the pot in the subsequent periods. Why is this the case? Without excluding winners, ex post inequality will be higher. Some individuals may receive the pot several times while other individuals may not receive it at all. Roscas thus minimize the wealth inequality of each draw. This is a good fairness property but it was not captured in our expected utility framework. The second remark is related to the interpretation of our behavioral model as a model of social pressure. We have inferred that roscas may help people to limit their expenditures in social redistributive obligations. This interpretation, however, raises further externality and reciprocity issues that our model has not addressed. 
For instance, since forming roscas reduces the frequency of income sharing, i.e., $m_{i}$ is spent less often, one can expect that the amount transferred to the poor $m_{i}$ increases. The amount to be shared $m_{i}$, as well as the reason why it is shared, should be somehow endogenous. Both remarks probably deserve some attention in future research.

\section{Conclusion}

Understanding the rationale underlying informal institutions in developing countries is one of the main challenges of development economics. Among these informal institutions, roscas are one of the most common but also one of the most puzzling. Since the paper by Besley, Coate and Loury (1993), the economic literature has been mostly driven by the durable good hypothesis. This literature asserts that the main benefit of roscas is to allow an early purchase of a durable good.

Empirical studies have suggested that self-control problems may be another motive to join roscas. For instance, Bouman (1995) asserts (page 375) that "Roscas also have illiquidity function. People with cash on their hands and afraid of greedy relatives, will purposely join a rosca to become illiquid. Contributions to a rosca are recognized by society as obligatory, and constitute a senior claim that must be respected by others." In his 1977 article, page 194, Bouman adds "By shedding liquidity through circulation in a rosca, one is (temporarily) safe from demands of support from the extended family." In a survey in South Africa (Aliber, 2001), rosca members mention self-control problems as the main motive for joining a rosca (see also Gugerty, 2000, for further evidence).

We have formalized this idea that roscas may be viewed as a commitment device which helps people to cope with their own self-control problems. We have introduced a model whereby people want to avoid spending too much money in the future purchase of a "superfluous" good. One way to avoid this future purchase is to commit in advance to contribute a fixed and inflexible amount at regular dates. This commitment device simply enables participants to decrease the available income that can be devoted to this purchase. Moreover, it is not difficult to understand that an optimal device is such that people can recover their contributions at some points in time, but not too often, because the extra-cash would tempt 
them to the purchase superfluous good too often. Hence, the best financial agreement requires a commitment on fixed contributions paid in advance many times and a high remuneration received at a single point in time. For stability purposes, the date of the remuneration must be randomized to assign same ex ante expected utility to every member. This is a typical random rosca.

An important point of our paper is the efficiency result we have obtained. Besley, Coate and Loury (1994) showed that a random rosca is sometimes better than organizing a credit market. But they agree that roscas are in general inefficient, implying that people can be better-off designing a Pareto-superior financial agreement. Instead, in our simple behavioral model, roscas turn out to be efficient, even in the absence of any motive for savings.

We should add that the durable good and the self-control hypotheses do not have to be mutually exclusive but may well complement each other. Think of the attitude of a rosca member when he has just received the pot. If he faces severe self-control problems, he may be tempted to splurge all this money on superfluous goods. This may explain why rosca members sometime commit in advance to buy an observable lumpy durable good with the pot. This commitment is often part of the deal. Rosca members might go so far as to monitor or supervise the purchases of the person receiving the pot, or to purchase it in kind for that person rather than giving him the cash (Gugerty, 2000). 


\section{A Proof of Lemma 1}

Consider an efficient lottery $\mathcal{L}_{i}^{*}=\left(K^{*}, p^{*}, T_{i}^{*}\right)$ for a given cost $x_{i}$. Let us partition any arbitrary set of transfers $T_{i}=\left\{t_{i}^{l}\right\}$ into two subsets $T_{i-}=\left\{t_{i}^{l} \in T_{i} \mid t_{i}^{l} \leq t_{i}^{1}\right\}$ and $T_{i+}=\left\{t_{i}^{l} \in T_{i} \mid t_{i}^{l}>t_{i}^{1}\right\}$. The proof proceeds in four steps. First, we show that $i$ 's utility is higher when receiving a positive transfer. Second, we prove that if an agent has to give (i.e. $t_{i}^{1}<0$ ), then he would give at most $t_{i}^{1}$. Third, we establish that, due to consumption smoothing, all transfers lower than $t_{i}^{1}$ must be the same, equal to $t_{i}^{1}$. Lastly, we derive the first order condition defining $t_{i}^{2}$.

Step 1: $u_{i}\left(y_{i}+t_{i}^{k *}\right)<u_{i}\left(y_{i}-m_{i}+t_{i}^{l *}\right)$ for every $t_{i}^{k *} \in T_{i-}^{*}$ and $t_{i}^{l *} \in T_{i+}^{*}$.

Suppose that $u_{i}\left(y_{i}+t_{i}^{k *}\right) \geq u_{i}\left(y_{i}-m_{i}+t_{i}^{l *}\right)$. Then suppose that, in state $l$, instead of assigning $t_{i}^{l *}$, the lottery assigns $t_{i}^{l *}+\epsilon$ with probability $q$ and $t_{i}^{k *}$ with probability $1-q$, where $q\left(t_{i}^{l *}+\epsilon\right)+(1-q) t_{i}^{k *}=t_{i}^{l *}$. For a $q$ sufficiently small (but positive) and $\epsilon$ high enough, $u_{i}\left(y_{i}-m_{i}+t_{i}^{l *}+\epsilon\right)>u_{i}\left(y_{i}+t_{i}^{k *}\right)$. This lottery dominates $\mathcal{L}_{i}^{*}$ while having same expected payoff, which in turn, implies that $\mathcal{L}_{i}^{*}$ cannot be optimal.

Step 2: If $t_{i}^{l *} \in T_{i-}^{*}$ then $t_{i}^{l *}=t_{i}^{1}$.

Suppose that this is not true. Suppose that there exists $t_{i}^{l *}<t_{i}^{1}$. Consider any arbitrary $t_{i}^{k *} \in T_{i+}^{*}$ (Recall that efficiency implies that $T_{i+}^{*}$ is no empty). Then there exists $\epsilon>0$ and $\epsilon^{\prime}>0$ sufficiently small such that $t_{i}^{k *}-\epsilon^{\prime} \in T_{i+}^{*}$ and $t_{i}^{l *}+\epsilon \in T_{i-}^{*}$ and $p(l) \epsilon+p(k) \epsilon^{\prime}=0$. The lottery $\mathcal{L}_{i}^{\prime}=\left(K^{*}, p^{*}, T_{i}^{\prime}\right)$ with $t_{l}^{\prime}=t_{i}^{l *}+\epsilon$, $t_{k}^{\prime}=t_{i}^{k *}-\epsilon^{\prime}$, and $t_{h}^{\prime}=t_{h}^{*}$ for every $h \neq l, k$ is assigns same expected payoff $x_{i}$ than $\mathcal{L}_{i}^{*}$. We show that $\mathcal{L}_{i}^{\prime}$ dominates $\mathcal{L}^{i *}$. Note that $u_{i}$ strictly concave implies

$$
u_{i}\left(y_{i}+t_{i}^{l *}+\epsilon\right)-u_{i}\left(y_{i}+t_{i}^{l *}\right)>u_{i}^{\prime}\left(y_{i}+t_{i}^{l *}+\epsilon\right) \epsilon
$$

and,

$$
u_{i}\left(y_{i}-m_{i}+t_{i}^{k *}\right)-u_{i}\left(y_{i}-m_{i}+t_{i}^{k *}-\epsilon^{\prime}\right)<u_{i}^{\prime}\left(y_{i}-m_{i}+t_{i}^{k *}-\epsilon^{\prime}\right) \epsilon^{\prime}
$$

Moreover,

$$
U_{i}\left(\mathcal{L}^{\prime}\right)-U_{i}\left(\mathcal{L}_{i}^{*}\right)=p(l)\left\{u_{i}\left(y_{i}+t_{i}^{l *}+\epsilon\right)-u_{i}\left(y_{i}+t_{i}^{l *}\right)\right\}+p(k)\left\{u_{i}\left(y_{i}-m_{i}+t_{i}^{k *}-\epsilon^{\prime}\right)-u_{i}\left(y_{i}-m_{i}+t_{i}^{k *}\right)\right\} .
$$

The last three equations imply:

$$
U_{i}\left(\mathcal{L}_{i}^{\prime}\right)-U_{i}\left(\mathcal{L}_{i}^{*}\right)>p(l) u_{i}^{\prime}\left(y_{i}+t_{i}^{l *}+\epsilon\right) \epsilon-p(k) u_{i}^{\prime}\left(y_{i}-m_{i}+t_{i}^{k *}-\epsilon^{\prime}\right) \epsilon^{\prime}
$$

We know since Step 1 that $t_{i}^{k *}-\epsilon^{\prime} \in T_{i+}^{*}$ and $t_{i}^{l *}+\epsilon \in T_{i-}^{*}$ imply $u_{i}\left(y_{i}+t_{i}^{l *}+\epsilon\right)<u\left(y_{i}-m_{i}+t_{i}^{k *}-\epsilon^{\prime}\right)$, which, in turn implies $u_{i}^{\prime}\left(y_{i}+t_{i}^{l *}+\epsilon\right)<u^{\prime}\left(y_{i}-m_{i}+t_{i}^{k *}-\epsilon^{\prime}\right)$. Moreover, by assumption $p(k) \epsilon=-p(l) \epsilon^{\prime}$. Therefore the left-hand side of (16) is positive, which contradicts that $\mathcal{L}_{i}^{*}$ is efficient.

Step 3: If $t_{i}^{l *} \in T_{i+}^{*}$ and $t_{i}^{k *} \in T_{i+}^{*}$, then $t_{i}^{l *}=t_{i}^{k *} \equiv t_{i}^{2}$. 
Suppose this is not true. Suppose that there exists $t_{i}^{l *} \in T_{i+}^{*}$ and $t_{i}^{k *} \in T_{i+}^{*}$ such that $t_{i}^{l *} \neq t_{i}^{k *}$. Then $\mathcal{L}_{i}^{*}$ is dominated by the (same expected payoff) $\mathcal{L}^{\prime}=\left(K^{*}, p^{*}, T_{i}^{\prime}\right)$ defined by $t_{i}^{k \prime}=t_{i}^{l \prime}=p(k) t_{i}^{k *}+p(l) t_{i}^{l *}, t_{i}^{h \prime}=t_{i}^{h *}$ for every $h \neq k, l$.

Step 4: Condition defining $t_{i}^{2}$.

Let $\mu(1-\mu)$ be the probability that $i$ transfers $t_{i}^{1}\left(t_{i}^{2}\right)$. By definition, $\mu$ and $t_{i}^{2}$ solves $\max _{\mu, t} \mu u_{i}\left(y_{i}+t_{i}^{1}\right)+$ $(1-\mu) u_{i}\left(y_{i}-m_{i}+t\right)$ subject to $\mu t_{i}^{1}+(1-\mu) t=x_{i}$. Substituting for $\mu$ as defined by the constraint in the objective function and differentiating with respect to $t$ yields (7) as a first order condition.

\section{B Proof of Lemma 2}

First, we show that any SFA $\mathbf{C}^{*}$ including non-fair lotteries is not stable. Consider the FA $C_{j}^{*}=\left(N_{j}^{*},\left\{\mathcal{L}_{i}^{*}\right\}_{i \in N_{j}}\right) \in$ $\mathbf{C}^{*}$ randomizing between transfers $t_{i}^{1}$ and $t_{i}^{2}$. Suppose that $x_{f}>0$ for one agent $f \in N_{j}$. Equation (9) implies that $x_{e}<0$ for at least another agent $e \in N_{j}$. Pick up any agent $h$ of another FA, $C_{k} \in \mathbf{C}^{*}$, randomizing between same transfers $t_{i}^{1}$ and $t_{i}^{2}$ in a lottery of cost $x_{h} \leq 0$. Design a new FA, $C_{j}^{\prime}=\left(S,\left\{\mathcal{L}_{i}^{\prime}\right\}_{i \in S}\right)$ similar to $C_{j}^{*}$, except that: 1) $f$ is replaced by $h$ in the group $\left.S ; 2\right)$ in one state of nature $l$ in which $f$ was previously assigned $t_{i}^{2}$, while $e$ receives $t_{i}^{1}$, define two state of nature $l_{1}$ and $l_{2}$. In $l_{1}$, e gets $t_{i}^{1}$ while $h$ gets $t_{i}^{2}$. Reversely, in $l_{2}, h$ is assigned $t_{i}^{1}$ while $e$ gets $t_{i}^{2}$. Choose the probabilities of states $l_{1}$ and $l_{2}$ such that $h$ gives less often with this FA, $C_{j}^{\prime}$, than with the former FA he belonged to $\mathbf{C}^{*}$. This translates to $\mu_{h}^{\prime}<\mu_{h}^{*}$, where $\mu_{h}^{\prime}\left(\mu_{h}^{*}\right)$ denotes $h$ 's probability to be assigned $t_{i}^{1}$ in $C_{j}^{\prime}\left(C_{j}^{*}\right)$. Therefore $U_{h}\left(\mathcal{L}_{h}^{\prime}\right)>U_{h}\left(\mathcal{L}_{h}^{*}\right)$. With $C_{j}^{\prime}, e$ is assigned $t_{i}^{1}$ less often (and gets $t_{i}^{2}$ more often) than in $C_{j}^{*}$, meaning that $\mu_{e}^{\prime}<\mu_{e}^{*}$ and, therefore $U_{e}\left(\mathcal{L}_{e}^{\prime}\right)>U_{e}\left(\mathcal{L}_{e}^{*}\right)$. Nothing changes for every other members $i \neq h$ of $C_{j}^{\prime}$ (i.e. they commit to same transfers in states $l_{1}$ and $l_{2}$ than in the former state $l$ ) who therefore gets the same expected payoff $U_{i}\left(\mathcal{L}_{i}^{\prime}\right)=U_{i}\left(\mathcal{L}_{i}^{*}\right)$. Hence, we have established that $\mathbf{C}^{*}$ is not stable according to Definition 3.

Second, we prove that a SFA with only fair lotteries is stable. Consider $\mathbf{C}^{*}$ where every FA $C_{j}^{*}=$ $\left(N_{j}^{*},\left\{\mathcal{L}_{k}^{*}\right\}_{k \in N_{j}}\right) \in \mathbf{C}^{*}$ includes people with same needs to randomize between transfers $t_{i}^{1}$ and $t_{i}^{2}$ (e.g. same utility function and revenue) who indeed randomize among these transfers with fair lotteries and corresponding probabilities denoted $\mu_{i}$ and $1-\mu_{i}$. Suppose that there exists $C_{j}^{\prime}=\left(S,\left\{\mathcal{L}_{k}^{\prime}\right\}_{k \in S}\right)$; such that $U_{k}\left(\mathcal{L}_{k}^{\prime}\right) \geq U_{k}\left(\mathcal{L}_{k}^{*}\right)$ for every $k \in S$ and $U_{h}\left(\mathcal{L}_{h}^{\prime}\right)>U_{h}\left(\mathcal{L}_{h}^{*}\right)$ for at least one $h \in S$. Obviously $C_{j}^{\prime}$ includes efficient lotteries $\mathcal{L}_{k}^{\prime}$ randomizing between $t_{i}^{1}$ and $t_{i}^{2}$. Denote the corresponding probabilities $\mu_{k}^{\prime}$ and $1-\mu_{k}^{\prime}$. Since $U_{k}\left(\mathcal{L}_{k}^{\prime}\right) \geq U_{k}\left(\mathcal{L}_{k}^{*}\right)$ implies $\mu_{k}^{\prime} \leq \mu_{i}$ for every $k \in S$, and $U_{h}\left(\mathcal{L}_{h}^{\prime}\right)>U_{h}\left(\mathcal{L}_{h}^{*}\right)$ implies $\mu_{h}^{\prime}<\mu_{i}$, then

$$
\sum_{k \in S}\left\{\mu_{k}^{\prime}\left(t_{i}^{1}\right)+\left(1-\mu_{k}^{\prime}\right) t_{i}^{2}\right\}>\sum_{k \in S}\left\{\mu_{i}\left(t_{i}^{1}\right)+\left(1-\mu_{i}\right) t_{i}^{2}\right\}
$$


Since lotteries $\mathcal{L}_{i}^{*}$ are fair, the right-hand side of (17) equals zero and, therefore, $\sum_{k \in S}\left\{\mu_{k}^{\prime} t_{i}^{1}+\left(1-\mu_{k}^{\prime}\right) t_{i}^{2}\right\}>0$. Thus, $C_{j}^{\prime}$ does not satisfy (9), which contradicts that $C_{j}^{\prime}$ is a FA.

\section{Proof of the Theorem}

The proof is organized in three steps. Step 1 extends the definition of a FA to a multi-period framework. Step 2 confirms that Lemma 1 still applies within the multi-period framework. Finally, step 3 shows that a SFA composed by roscas is stable.

Step 1 Extension of the definition of a FA to a multi-period framework.

A multi-period FA, $C_{j}=\left(N_{j},\left\{\mathcal{L}_{i}\right\}_{i \in N_{j}}\right)$ is still defined by a group of agents $N_{j}$. But now, each member faces a sequence of per-period lotteries. For simplicity, it is still denoted $\mathcal{L}_{i}$. Each per-period lottery part of this sequence might depend on previous draws. Without loss of generality, all these lotteries can be defined on a common set of states of nature $K_{j t}$. However, the probability measure on $K_{j t}$ might be contingent on the previous realized states of nature.

Since the contracting choices occur only at date 0 the choices are guided by probabilities computed at date 0 . Formally, denoting $p_{j t}$ the probability at date 0 that state $l \in K_{i t}$ is drawn at date $t$, the discounted expected utility of an arbitrary member $i$ of the FA $C_{j}=\left(N_{j},\left\{\mathcal{L}_{i}\right\}_{i \in N_{j}}\right)$ is:

$$
U_{i}\left(\mathcal{L}_{i}\right)=\sum_{t=1}^{\infty} \delta^{t} \sum_{l \in K_{j t}} p_{j t}(l) v_{i}\left(y_{i}+t_{i}^{l}\right),
$$

Step 2 Lemma 1 still applies within the multi-period framework.

Any efficient sequence of lotteries $\mathcal{L}_{i}$ still maximizes (18) subject to a sequence of per-period expected payoffs $\left\{x_{i t}\right\}_{t \in \mathbb{N}}$ (viewed at date 0 ) defined by $x_{i t}=\sum_{l \in K_{j t}} p_{j t}(l) t_{i t}^{l}$. Clearly, it is equivalent to maximizing perperiod expected utility (viewed at date 0), namely $\sum_{l \in K_{j t}} p_{j t}(l) v_{i}\left(y_{i}+t_{i}^{l}\right)$, subject to the per-period expected payoffs $x_{i t}$ for every date $t$. Hence Lemma 1 applies.

Step 3 A SFA composed by roscas is stable.

Suppose that SFA composed by roscas is not stable. Then there exists a FA, $C_{j}^{\prime}=\left(S,\left\{\mathcal{L}_{i}^{\prime}\right\}_{i \in S}\right)$ such that every member $i \in S$ is not worse off and at least one member $h \in S$ is strictly better off than with a SFA with only roscas. Then $C_{j}^{\prime}$ include efficient lotteries, so that $i$ 's (discounted) expected utility simplifies to:

$$
U_{i}\left(\mathcal{L}_{i}\right)=\sum_{t=1}^{\infty} \delta^{t}\left\{\mu_{i t}^{\prime} u_{i}\left(y_{i}+t_{i}^{1}\right)+\left(1-\mu_{i t}^{\prime}\right) u_{i}\left(y_{i}-m_{i}+t_{i}^{2}\right)\right\}
$$

where $\mu_{i t}^{\prime}\left(1-\mu_{i t}^{\prime}\right)$ denotes the probability at date 0 that $i$ is assigned $t_{i}^{1}\left(t_{i}^{2}\right)$ at date $t$. On the other hand, (15) tells us that, to a member $i$, a rosca yields a (discounted) expected utility:

$$
U_{i}\left(\mathcal{L}_{i}^{*}\right)=\sum_{t=1}^{\infty} \delta^{t}\left\{\mu_{i} u_{i}\left(y_{i}+t_{i}^{1}\right)+\left(1-\mu_{i}\right) u_{i}\left(y_{i}-m_{i}+t_{i}^{2}\right)\right\},
$$


where $\mu_{i}=\frac{n_{i}-1}{n_{i}}$ (Recall that $n_{i}$ denotes the optimal size of the rosca for individual $i$ ).

Now, by assumption, $U_{i}\left(\mathcal{L}_{i}^{\prime}\right) \geq U_{i}\left(\mathcal{L}_{i}^{*}\right)$ for every $i \in S$ and $U_{h}\left(\mathcal{L}_{h}^{\prime}\right)>U_{h}\left(\mathcal{L}_{h}^{*}\right)$ for at least one $h \in S$. Combining the above two inequalities with (19) and (20) implies $\sum_{t=1}^{\infty} \delta^{t} \mu_{i t}^{\prime} \leq \sum_{t=1}^{\infty} \delta^{t} \mu_{i}$ and $\sum_{t=1}^{\infty} \delta^{t}\left(1-\mu_{i t}^{\prime}\right) \geq$ $\sum_{t=1}^{\infty} \delta^{t}\left(1-\mu_{i}\right)$; with a strict inequality for at least one individual $h \in S$. These inequalities in turn imply:

$$
\sum_{i \in S} \sum_{t=1}^{\infty} \delta^{t}\left\{\mu_{i t}^{\prime} t_{i}^{1}+\left(1-\mu_{i t}^{\prime}\right) t_{i}^{2}\right\}>\sum_{i \in S} \sum_{t=1}^{\infty} \delta^{t}\left\{\mu_{i} t_{i}^{1}+\left(1-\mu_{i}\right) t_{i}^{2}\right\} .
$$

In other words, $\sum_{i \in S} \sum_{t=1}^{\infty} \delta^{t} x_{i t}^{\prime}>\sum_{i \in S} \sum_{t=1}^{\infty} \delta^{t} x_{i t}^{*}$, where $x_{i t}^{\prime}$ and $x_{i t}^{*}$ are the respective expected payoffs (viewed from date 0 ) of the per-period lotteries played at date $t$. Since they sum-up to 0 for roscas, i.e. $x_{i t}^{*}=0$ for every $t$, at least one per-period lottery expected payoff $x_{i t}^{\prime}$ is strictly positive while the others are non-negative, which contradicts the supposition that $C_{j}^{\prime}$ is a FA. 


\section{References}

Adams, D.W., and M.L. Canavesi de Sahonero (1978) 'Rotating savings and credit associations in Bolivia.' Savings and Development 2(4), 219-236

Ainslie, G. W. (1992) Picoeconomics (Cambridge, United Kingdom: Cambridge University Press)

Akerlof, G. (1991) 'Proscrastination and obedience.' American Economic Review Papers and Proceedings 81(2), 1-19

Aliber, M. (2001) 'Rotating savings and credit associations and the pursuit of self-discipline.' African Review of Money Finance and Banking (2001), 51-72

Anderson, S., and J.M. Baland (2002) 'The economics of roscas and intrahousehold resource allocation.' Quarterly Journal of Economics 117(3), 963-995

Anderson, S., J.M. Baland, and K.O. Moene (2002) 'Sustainability and organizational design in roscas: Some evidence from Kenya.' Manuscript, University of Namur

Ashraf, N., N. Gons, D. Karlan, and W. Yin (2003) 'A review of commitment savings products in developing countries.' Asian Development Bank Economics and Research Department Working paper No. 45

Ashraf, N., D. Karlan, and W. Yin (2004) 'Tying odysseus to the mast: Evidence from commitment savings product in the Philippines.' Manuscript, Harvard University

Besley, T. (1995) 'Nonmarket institutions for credit risk sharing in low-income countries.' Journal of Economic Perspectives 9(3), 115-127

Besley, T., S. Coate, and G. Loury (1993) 'The economic of rotating savings and credit associations.' American Economic Review 83(4), 792-810

— (1994) 'Rotating savings and credit associations, credit markets and efficiency.' Review of Economic Studies 61, 701-719

Bouman, F. (1977) 'Indigenous savings and credit societies in the third word: A message.' Saving and Development 1(4), 181-218

- (1995) 'Rotating and accumulating savings and credit associations: A development perspective.' World Development 23(3), 371-384

Calomiris, C. W., and I. Rajaraman (1998) 'The role of roscas: Lumpy durables or event 
insurance?' Journal of Development Economics 56, 207-216

Elster, J. (1998) 'Emotions and economic theory.' Journal of Economic Literature $36(1), 47-74$

Fafchamps, M. (1995) 'The rural community, mutual assistance, and structural adjustment.' In State, Markets, and Civil Institutions: New Theories, New Practices, and their Implications for Rural Development, ed. A. de Janvry, S. Radwan and E. Thorbecke (Mc Millan Press)

Genicot, G., and D. Ray (2003) 'Group formation in risk-sharing arrangements.' Review of Economic Studies 70, 87-113

Gugerty, M. K. (2000) 'You can't save alone: Testing theories of rotating savings and credit associations.' Manuscript, Harvard University

Handa, S., and C. Kirton (1999) 'The economics of rotating saving and credit associations: Evidence from the jamaican 'partner'.' Journal of Development Economics 60(1), 173-194

Henry, A., G.H. Tchente, and P. Guillerme (1990) 'La société des amis : étude des tontines à enchères du Cameroun.' Document de travail, Caisse centrale de coopération économique, Centre d'études financières, économiques et bancaires, Université de Rennes 1

James, W. (1979) Kwanim Pa, The Making of the Uduk People (Oxford, United Kingdom: Clarendon Press)

Klonner, S. (2003) 'Rotating saving and credit associations when participants are risk averse.' International Economic Review 44(3), 979-1005

Kuper, H., and S. Kaplan (1944) 'Voluntary associations in an urban township.' African Studies 3, 178-186

Laibson, D. (1997) 'Golden eggs and hyperbolic discounting.' Quartely Journal of Economic $62,443-477$

Levenson, A.R., and T. Besley (1996) 'The anatomy of an informal financial market: Rosca participation in Taiwan.' Journal of Development economics 51(1), 45-68

Luttmer, E., and T. Mariotti (2004) 'Efficiency and equilibrium when preferences are time-inconsistent.' IDEI working paper 335, University of Toulouse

Nagarajan, G., R.L. Meyer, and D.H. Graham (1999) 'Does membership homogeneity matter for group-based financial services? evidence from Gambia.' African Development 
Review 11(1), 87-102

O’Donoghue, T., and M. Rabin (1999) 'Doing it now or later.' American Economic Review 89(1), 103-124

Parkin, D. J. (1972) Palms, Wine, and Witnesses (London, United Kingdom: Chandler Publishing)

Phelps, E.S., and R.A. Pollack (1968) 'On the second-best national saving and game-equilibrium growth.' Review of Economic Studies 35, 185-199

Platteau, J. P. (1996) 'Traditional sharing norm as an obstacle to economic growth in tribal societies.' Cahier de recherche du CRED, University of Namur

- (2000) Institutions, Social Norms and Economics Development (USA: Harwood Academic Publisher)

Scott, J. (1976) The Moral Economy of the Peasant (Cambridge, Massachusetts, USA: Yale University Press)

Thaler, R. H. (1992) The Winner's Curse: Paradoxes and Anomalies of Economic Life (Princeton, USA.: Princeton University Press)

Wright, G.A.N., and L.N. Mutesasira (2001) 'The relative risks to the savings of poor people.' Small Enterprise Development 12(3), 33-45 


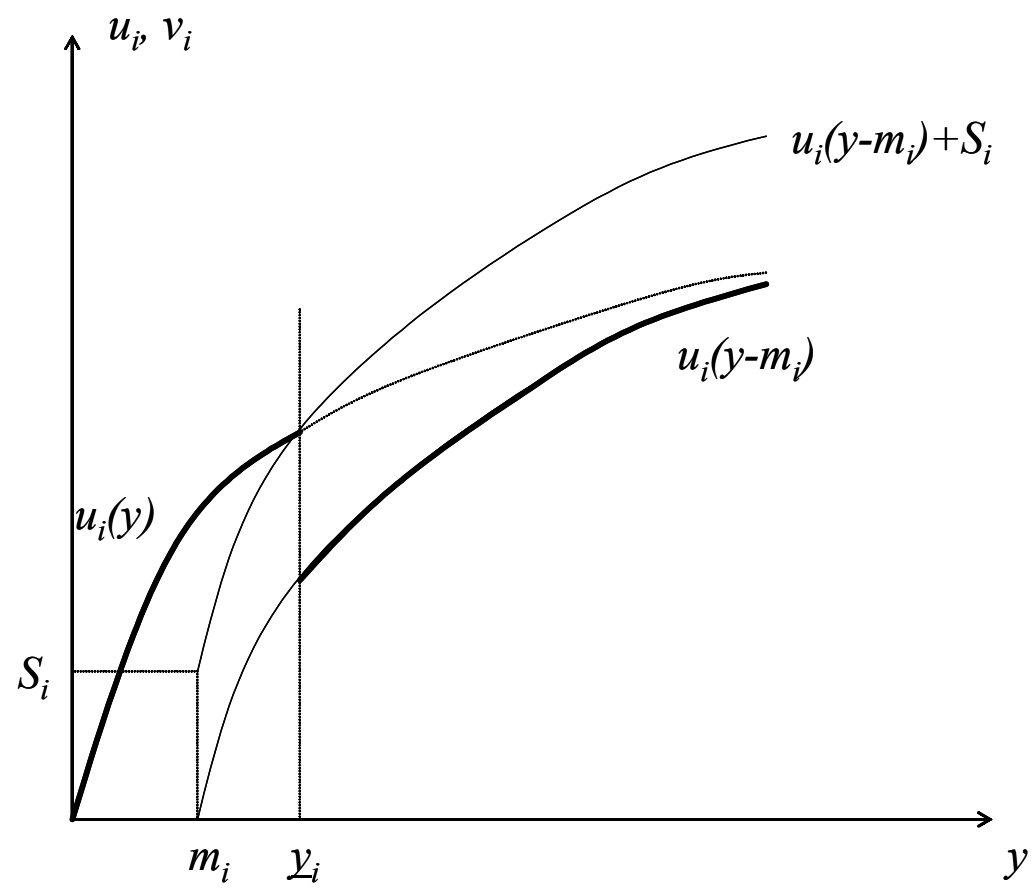

Figure 1

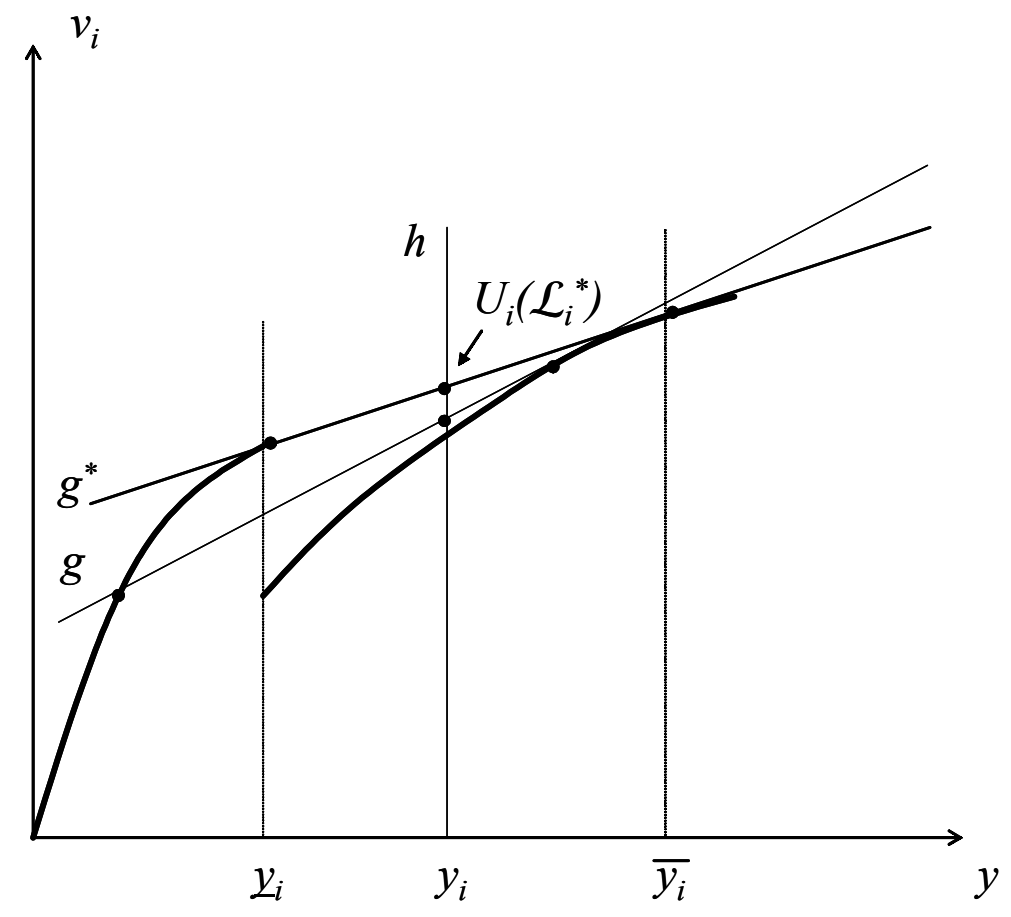

Figure 2 